\title{
Vestibular paresis: a clinical feature of Wernicke's disease
}

\author{
CLAUDE GHEZ \\ From the Division of Neurology, Cleveland Metropolitan General Hospital, and \\ Case Western Reserve University School of Medicine, Cleveland, Ohio, U.S.A.
}

Wernicke's disease is a well-defined clinical and pathological entity, and its aetiology has been conclusively traced to thiamine deficiency (Phillips, Victor, Adams, and Davidson, 1952). Its essential features are the subacute onset of confusion, ophthalmoplegia and/or nystagmus, and ataxia of stance and gait. It invariably occurs against a background of malnutrition and often chronic alcoholism. Ophthalmoplegia, ataxia, and the global confusion respond readily to thiamine administration, but the patient is often left with a conspicuous disorder in memory (Korsakoff's psychosis), and not infrequently some degree of ataxia when attempting to walk on a narrow base (heel to toe).

In the acute stages of the disease there is frequently a striking discrepancy between the patient's ability to stand and walk and his ability to perform tests designed to assess cerebellar function-that is, heel-to-shin, finger-to-nose, etc. The patient may literally be unable to take even a few steps without support; his legs are rigidly held wide apart, the body pitched forward as he clutches the nearest solid object for fear of falling. In a study of 245 patients with Wernicke's disease by Victor, Adams, Collins, and Silby (to be published), it was found that ataxia of stance and gait occurs in $87 \%$, whereas ataxia of the lower extremities in only $20 \%$.

One interpretation of this finding attributes the ataxia of stance and gait to lesions in the midline cerebellar vermis, and the ataxia of the lower extremities to an extension of the lesion into more lateral areas of the anterior lobes (Victor, Adams, and Mancall, 1959). Vestibular function, which is known to be of paramount importance in the regulation of postural adjustments, has not heretofore been determined. This study was undertaken to evaluate vestibular function in the acute and chronic stages of Wernicke's disease.

\section{MATERIAL AND METHODS}

The subjects were 17 chronically malnourished patients admitted to Cleveland Metropolitan General Hospital

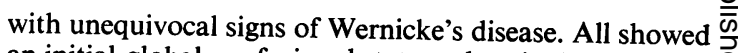
an initial global confusional state and variable degrees of $\mathbb{\infty}$ memory loss as a persistent finding. All patients had nystagmus and severe ataxia of gait as well as signs of ${ }^{\infty}$ mild polyneuropathy. Ophthalmoplegia was seen in $12 \vec{\circ}$ patients (bilateral abducens palsies in 11 and total external ophthalmoplegia in one) and lasted from one to $\vec{\omega}$ seven days. Mild cerebellar signs of the lower extremities could be elicited in nine and of the upper extremities in two. Vertigo was not a complaint in any. Thiamine hydrochloride $(100 \mathrm{mg})$ was administered intramuscularly upon admission to all patients and orally for several days thereafter. All patients were examined neurologically io $\vec{\omega}$ a serial fashion. Head injuries were not a factor in any of $\vec{A}$ the patients and routine skull films were normal. A 1 通 patients had been hospitalized throughout the course of this study during which time they received an adequate diet and no alcohol.

Control subjects were 12 chronic alcoholic patients seven with delirium tremens and five with alcoholio cerebellar degeneration (Victor et al., 1959). The latte group had no impairment in mental function or ophthalmoplegia. Their neurological deficit consisted of mild ataxia of stance and gait with an associated symmetrical ataxia of legs and to a lesser extent of the arms. The onset of the disturbance had been gradual and no discernible episode of Wernicke's disease had occurred. No significant change in the severity of their ataxia was noted during the course of their hospital stay.

Vestibular function was assessed by means of a standard ice water caloric test. The ears were irrigated for 30 seconds with $5 \mathrm{ml}$. ice water with at least a five minute interval between the testing of each ear. The patient was instructed to fix his gaze on a point straight ahead and the time elapsing between the time of injection and end of the ensuing nystagmus was determined. Past pointing with eyes closed before and after stimulation was evaluated.

Tests were performed on more than one occasion in 14 patients. Four patients were tested only twice; the other 10 were tested on multiple occasions, on alternate days at the beginning and at weekly and monthly intervals later in the course of their illness.

Five patients were tested for directional preponderance by means of a modification of the method of Fitzgerald and Hallpike (1942) in which the ears were alternately irrigated with $75 \mathrm{ml}$. water at 30 and $44^{\circ} \mathrm{C}$.

With one exception, none of our patients had any hearing deficit by history or on routine clinical testing 
(Weber, Rinné, and Schwabach). Pure tone audiograms were obtained in six patients and the more sensitive Von Bekesy audiograms, tone decay, and Short Increment Sensitivity index were done in three cases.

\section{RESULTS}

1. RESPONSES TO ICE WATER IRRIGATION (a) $A b$ normalities on initial testing (Table I) Despite some variation in the time at which the first test was carried out, all 17 patients showed profound abnormalities in vestibulo-ocular responses. In 11 patients the responses were absent bilaterally and in six patients unilateral unresponsiveness was seen (even in the first few days following hospitalization). The presence of abducens palsies did not interfere with the reflex which could be recognized in the adducting eye.

TABLE I

INITIAL RESPONSES AND ONSET OF RECOVERY

\begin{tabular}{ccc}
\hline \multirow{2}{*}{$\begin{array}{c}\text { Absent response on initial } \\
\text { examination }\end{array}$} & \multicolumn{2}{c}{ Patients } \\
\cline { 2 - 3 } & $($ no. $)$ & $(\%)$ \\
\hline (17 patients) & 17 & 100 \\
Bilateral & 11 & $64 \cdot 7$ \\
Unilateral & 6 & $35 \cdot 3$ \\
Onset of recovery \\
(10 patients) & & \\
Range & \multicolumn{2}{c}{} \\
7 patients & 6 days-2 months \\
\hline
\end{tabular}

Three patients showed past pointing towards the side of the ice water irrigation, even though nystagmus was completely absent. Vertigo, however, never occurred without nystagmus.

In contrast, the responses of all control subjects were within normal limits. In 10, contralateral nystagmus developed on calorization and lasted between two and three minutes. Asymmetries between ears greater than 20 seconds were not seen. Two patients suffering from delirium tremens who were heavily sedated with paraldehyde and chlordiazepoxide showed ipsilateral tonic-ocular deviation lasting about two minutes following irrigation.

(b) Mode of recovery Some degree of recovery of vestibular function was ascertained by serial caloric testing in 10 patients. The onset of recovery varied from six to 60 days, and in seven patients it began in the second week following thiamine administration (Table I).

In seven patients, the tests were carried out at intervals sufficiently short so that the manner of evolution of the caloric responses could be assessed. These data are illustrated by five representative cases in Fig. 1 and indicate that recovery occurs in a gradual, often asymmetrical, fashion and can be prolonged and incomplete. On occasion, the duration of nystagmus was longer than normal, although not necessarily in relation to directional preponderance (Fig. 3). In the early phases of recovery, marked irregularity and a reduced

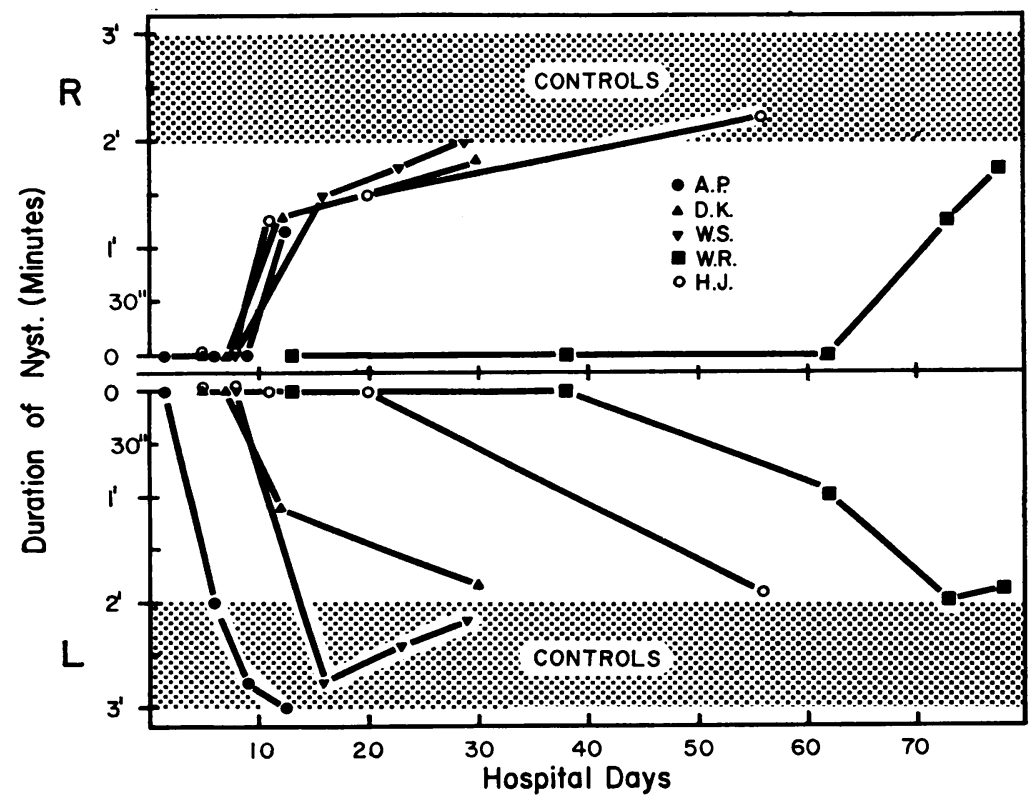

FIG. 1. Evolution of caloric responses-selected cases. The duration of nystagmus represents the time from the beginning of the injection to the end of the ensuing nystagmus. 
amplitude of the nystagmic movements were commonly observed and could be easily appreciated by visual inspection alone.

The cumulative data from all patients are presented graphically in Figure 2. It was found that after the tenth day following therapy the proportion of patients showing abnormal caloric responses started to decline. At eight months, $20 \%$ were abnormal. It must be stated that this latter figure represents an approximation of what is to be expected in the chronic phase of Wernicke's disease in view of the fact that at eight months a smaller number of patients were available for testing than in the acute stages of the disease. Caloric responses were deemed abnormal either if the duration of nystagmus was less than $1 \frac{1}{2}$ minutes or if an asymmetry greater than 30 seconds between sides was found. Abnormal responses consisted in the complete absence of vestibulo-ocular response on one or both sides, with the exception of six patients at $\mathbf{1 0}$ days, one at 20 days, and one at four months.

2. DIFFERENTIAL CALORIC RESPONSES. DIRECTIONAL PREPONDERANCE (Fig. 3) Significant directional preponderance was found in only one of five patients in whorn it was specifically sought during recovery. In this patient is was associated with depressed responses to both warm and cold stimuli on one side.

3. AUDIOMETRY With one exception, audiometry failed to reveal any significant abnormality despite the concurrent existence of severe vestibular paresis. The exceptional patient had developed hearing loss several years previously which was ascribed to otosclerosis. Furthermore in this patient there was an improvement in vestibular responses on one side over the period of observation without corresponding improvement in hearing.

4. CLINICAL CORRELATIONS Ophthalmoplegia, which was present in 12 patients, was transient in all cases. Nystagmus, polyneuropathy, and Korsakoff's amnestic psychosis were persistent despite the return of vestibulo-ocular responses. None of these signs, therefore, showed a temporal relationship with the vestibular defect.

On the other hand, in nine patients the gross initial ataxia of gait improved concomitantly with the return of caloric responses. After the return to normal of vestibular responses, the patients either had no abnormality of gait or more commonly a mild abnormality taking the form of a slightly widened base, slow shuffling steps, and difficulty walking tandem. Only at this time was their gait similar to that seen in our patients with alcoholic

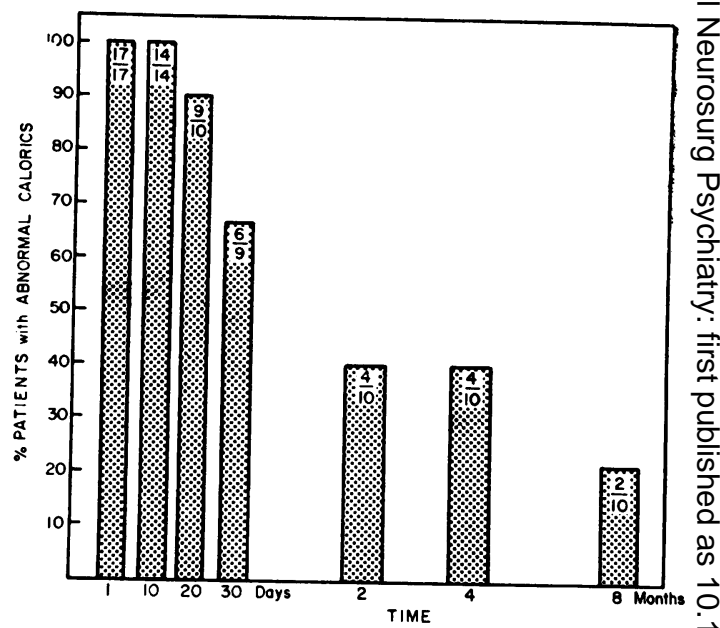

FIG. 2. Evolution of caloric responses-cumulative data. $\vec{\omega}$ Caloric responses were deemed abnormal if the duration of nystagmus was less than $1 \mathrm{~min} 30 \mathrm{sec}$ or if the difference? between the two sides was greater than $30 \mathrm{sec}$.
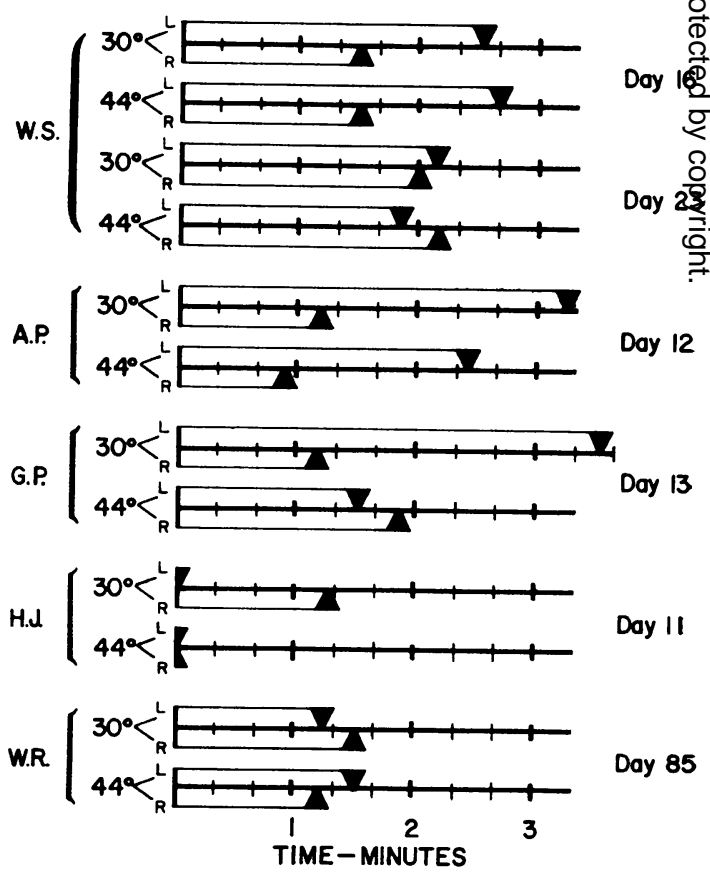

Day 85

FIG. 3. Differential caloric responses-selected cases. $A$ significant degree of directional preponderance is seen only in patient G.P. where the pattern of response is one of 'combined lesions' (see text). Directional preponderance was probably not present in patient $H$.J. because he showed only 20 seconds of irregular nystagmus upon right-sided cold stimulation. 
cerebellar degeneration. It should, however, be stated that one of our patients showed complete recovery of gait while his vestibular responses had only partially recovered.

\section{DISCUSSION}

Neither single case reports of Wernicke's disease nor large series of cases (Campbell and Russell, 1941; Jolliffe, Wortis, and Fein, 1941; Riggs and Boles, 1944; Cruikshank, 1950; Malamud and Skillicorn, 1956) have previously called attention to the existence of vestibular abnormalities. A possible exception to this statement is the case of Chavany, Messimy, and Lefranc (1958), which was probably a case of Wernicke's disease in which bilateral caloric hyporesponsiveness is merely recorded. The cases presented here indicate that such an abnormality is an extremely common if not a constant sign of acute Wernicke's encephalopathy.

An ice water test was used because the more elaborate techniques of bithermal stimulation do not appear to be necessary for the clinical demonstration of the disturbance, and because of the ease with which it can be performed at the bedside. Differential caloric tests at 30 and $44^{\circ}$ do provide information regarding 'directional preponderance' and are said to be more precise (Cawthorn, Dix, Hallpike, and Hood, 1956) and to cause less discomfort than ice water. Furthermore, the latter is said to occasionally cause a reduction in vestibular afferent input by direct action upon the vestibular nerve (Gernandt, 1949). In addition, there is a theoretical advantage in using warm and cold stimuli, since the former has been found to cause an increase while the latter a decrease in frequency of discharge recorded in the ampullar nerves from the horizontal semi-circular canals (Gernandt, 1949).

Nevertheless, it has been shown that the effectiveness of ice water is only slightly greater than that of water at $30^{\circ}$, and that the amount of water is of relatively little consequence in relation to the duration of the ensuing nystagmus (Jonkees, 1949). In our experience the difference between the duration of nystagmus or the discomfort resulting from the two cold stimuli (ice water and water at $30^{\circ} \mathrm{C}$ ) was never significant. Finally, had direct effect of ice water on the vestibular nerve actually occurred, it would have produced the same effect as that resulting from labyrinthine stimulation itself - that is, inhibition of vestibular discharges.

Despite the common occurrence of nystagmus during alcohol intoxication (Bernhard and Goldberg, 1934; Aschan, 1958) and withdrawal (Goldberg, 1961), these conditions do not appear to contribute to the vestibular disorder, since our subjects were not intoxicated and control subjects in delirium did not show this abnormality. Hepatic encephalopathy, another common metabolic complication of chronic alcoholism, does not interfere with vestibulo-ocular responses (Conomy and Swash, 1968), nor was it present in our cases.

The absence of vertigo and/or deafness suggests that pathological changes in end-organ or vestibular nerve are unlikely to account for our observations (Aschan, 1967). The relatively rapid rate of improvement, in contrast with the slow evolution of nutritional polyneuropathy, and the absence of skull fractures, are further arguments against the existence of a nutritional or traumatic insult to these structures.

The pathological findings in Wernicke's disease may indicate the site and nature of the lesions responsible for the vestibular dysfunction. In a detailed and extensive study, Victor et al. (to be published) found that among 38 cases in whom specific brain-stem nuclei were examined $71 \cdot 1 \%$ showed definite lesions of the medial vestibular nucleus. The lateral, superior and spinal nuclei were involved in $50.0,35.7$, and $29.7 \%$ respectively. It should be emphasized that, while the histological features of Wernicke's disease may be in the nature of frank necrosis and demyelination in nuclear areas, the vestibular lesion is of a relatively milder degree. It consists primarily in relatively symmetrical affection of a triangular zone which may include the dorsal motor nucleus of the vagus and extends laterally into the vestibular complex. Mild nerve cell and myelin loss associated with a conspicuous increase in microglia and astrocytes are seen. This change is similar to that seen in the abducens nucleus. In so far as the vestibulospinal tract originates from the lateral vestibular nucleus (Brodal, Pompeiano, and Walberg, 1962), the occasional preservation of past pointing may bear some relation to the lower incidence of involvement of this structure.

Following the historic studies of Prickett (1934), Alexander, Pijoan, and Meyerson (1938) pointed out the similarity between the histopathological changes of Wernicke's disease and those resulting from thiamine deficiency in the experimental animal, Phillips et al. (1952) demonstrated that the human condition responded specifically to thiamine administration.

Although the affection of vestibular nuclei has long been known (Prickett, 1934; Zimmerman, 1939; Swank and Prados, 1942), the only experimental studies of vestibular function per se in athiaminotic animals are those of Church $(1933,1935)$. Rats, given an autoclaved yeast diet deficient in thermolabile thiamine, lost their labyrinthine-righting 
reflexes while the neck reflexes remained intact. Post-rotatory nystagmus was found to increase in proportion to the duration of the deficient state. If the animals were allowed to recover and a second bout of deficiency was produced the animals failed completely to develop post-rotatory nystagmus. The changes were considered to be reversible following treatment with non-autoclaved yeast.

While the work of Swank and Prados (1942) suggested that histological abnormalities occurred in the labyrinthine cristae, vestibular nerves, and nuclei in thiamine deficient pigeons, it has been pointed out (Dreyfus and Victor, 1961) that the changes described were relatively minor and may have been attributable to the well-known capriciousness of the gold and silver stains which were used exclusively.

In the rat, the vestibular complex is selectively vulnerable to thiamine depletion. The destruction of neurones and myelinated fibres is accompanied by an intense glial reaction and macrophage activity. The thiamine dependent enzyme transketolase has been reported to be depressed selectively in the lateral pontine tegmentum at an early stage of deficiency (Dreyfus, 1965). The recent electron microscopic study of the vestibular nuclei in thiamine deficient animals by Tellez and Terry (1968) has direct bearing upon our findings. These authors present evidence that the earliest changes affect the presynaptic endings and axons within the vestibular nuclei. The synaptic boutons were enlarged, their membranes thickened, and synaptic vesicles were either absent or markedly reduced in number. In addition, the endings were seen to contain unusual (electron-dense) tubular structures with periodic darker bands. Degenerative changes in axons were also reported, although neuronal bodies and glia were unremarkable. It is highly probable that these early axonal and synaptic changes occur in the human disease as well as in the experimental animal. This would explain the occurrence of a functional disturbance of the vestibular system most commonly associated with peripheral lesions. We attribute the high incidence of recovery of vestibular and extraocular muscle function to the mild affection of neurones in the appropriate cranial nerve nuclei in Wernicke's disease.

Vestibular paresis appears to be a very common, if not universal, finding in the acute stages of Wernicke's disease. This sign, which can be elicited at the bedside, seems to correlate with the early severe ataxia of gait seen in this condition. However, it is clear that other abnormalities contribute to the instability of stance and gait. Indeed polyneuropathy, cerebellar disease, muscle weakness, and postural hypotension (Gravallese and Victor, 1957) are frequent findings in such patients and undoubtedly exacerbate any functional disturbance brought about ${ }^{\mathbb{Q}}$ by the vestibular defect.

We urge the adoption of the term 'vestibular $\stackrel{\text { ? }}{=}$ paresis', which is less anatomically restrictive than 'canal paresis', to indicate a global decrease in ${ }_{\mathscr{S}}$ sensitivity of vestibulo-ocular responses to both warm and cold stimuli.

\section{SUMMARY}

Caloric responses were evaluated in 17 patients witho Wernicke's disease and in 12 alcoholic controls. Allo patients with Wernicke's disease showed either, unilateral or bilateral unresponsiveness in the first $\stackrel{\Phi}{\varnothing}$ week of hospitalization. The course of recovery of function is outlined. It is felt to contribute to the severe instability of stance and gait which is present. in these patients.

These findings are best explained on the basis of the common lesions in the vestibular nuclei and the recently reported changes in synaptic terminals ando axons seen in these nuclei in thiamine deficient $\omega$ animals.

I am deeply grateful to Professor Maurice Victor for $\frac{\mathbb{R}}{\mathrm{m}}+$ constant encouragement as well as for his help comments and criticisms of the manuscript.

\section{REFERENCES}

Alexander, L., Pijoan, M., and Meyerson, A. (1938). Beri-beri and scurvy. An experimental study. Trans. Amer. Neurol. Ass., क्षि, 135-139.

Aschan, G. (1958). Different types of alcohol nystagmus. Acta $\square$ oto-laryng. (Stockh.), Suppl. No. 140, 69-78. (1967). Clinical vestibular examinations and their results. Ibid., Suppl. No. 224, 56-66.

Bernhard, C. G., and Goldberg, L. (1934). Nystagmus spontané par, suite d'intoxication aigue par l'alcool. Acta med. scand., 84, , 36-44.

Brodal, A., Pompeiano, O., and Walberg, F. (1962). The Vestibular Nuclei and Their Connections. Anatomy and Functional Cor- $\overline{\bar{O}}$ relations (pp. 193). Oliver and Boyd, Edinburgh.

Campbell, A. C. P., and Russell, W. R. (1941). Wernicke's encephalopathy: the clinical features and their probable relationship? to vitamin B deficiency. Quart. J. Med., 10, 41-64.

Cawthorn, T., Dix, M. R., Hallpike, C. S., and Hood, J. D. (1956). The investigation of vestibular function. Brit. med. Bull., 12, 131-142.

Chavany, J. A., Messimy, R., and Lefranc, E. (1958). Grand syndrome. cérébelleux pur au cours d'une encéphalopathie alcoolique chronique avec troubles mentaux du type Korsakowien. Rev neurol., 98, 689-692.

Church, C. F. (1933). Vestibular function in beri-beri. Proc. Soc.윽 Exp. Biol. (N.Y.), 30, 1158-1160.

(1935). Functional studies of the nervous system in experimental 0 beri-beri. Amer. J. Physiol., 111, 660-680.

Conomy, J. P., and Swash, M. (1968). Reversible decerebrate and decorticate postures in hepatic coma. New Engl. J. Med., 278,O 876-879. Cruikshank, E. K. (1950). Wernicke's encephalopathy. Quart. J. $\mathrm{N}$
Med., 19, 327-338.

Dreyfus, P. M., and Victor, M. (1961). Effects of thiamine deficiency on the central nervous system. Amer. J. clin. Nutr., 9, 414-425.

(1965). The regional distribution of transketolase in the normaiN and the thiamine deficient nervous system. $J$. Neuropath. exp. Neurol., 24, 119-129. 
Fitzgerald, G., and Hallpike, C. S. (1942). Studies in human vestibular function. I. Observations on the directional preponderance ('Nystagmusbereitshaft'), of caloric nystagmus resulting from cerebral lesions. Brain, 65, 115-137.

Gernandt, B. (1949). Response of mammalian vestibular neurons to horizontal rotation and caloric stimulation. J. Neurophysiol., 12, 173-184.

Goldberg, L. (1961). Alcohol, tranquilizers and hangover. Quart. J. Stud. Alcohol, Suppl. No. 1, 37-56.

Gravallese, M. A., Jr., and Victor, M. (1957). Circulatory studies in Wernicke's encephalopathy. With special reference to the occurrence of a state of high cardiac output and postural hypotension. Circulation, 15, 836-844.

Jolliffe, N. Wortis, H., and Fein, H. D. (1941). The Wernicke syndrome. Arch. Neurol. Psychiat. (Chic.), 46, 569-597.

Jonkees, L. B. W. (1949). Which is the preferable method of performing the caloric test? Arch. Otolaryng., 49, 594-608.

Malamud, N., and Skillicorn, S. A. (1956). Relation between the Wernicke and the Korsakoff syndrome. Arch. Neurol. Psychiat. (Chic.), 76, 585-596.

Phillips, G. B., Victor, M., Adams, R. D., and Davidson, C. S. (1952). A study of the nutritional defect in Wernicke's syndrome. J. Clin. Invest., 31, 859-871.
Prickett, C. O. (1934). The effect of a deficiency of vitamin B upon the central and peripheral nervous systems of the rat. Amer. J. Physiol., 107, 459-470.

Riggs, H. E., and Boles, R. S. (1944). Wernicke's disease. A clinical and pathological study of 42 cases. Quart. J. Stud. Alcohol, 5, 361-370.

Swank, R. L., and Prados, M. (1942). Avian thiamine deficiency. II. Pathologic changes in the brain and cranial nerves (especially the vestibular) and their relation to the clinical behavior. Arch. Neurol. Psychiat. (Chic.), 47, 97-131.

Tellez, I., and Terry, R. D. (1968). Fine structure of the early changes in the vestibular nuclei of the thiamine deficient rat. Amer. $J$. Path., 52, 777-794.

Victor, M., Adams, R. D., and Mancall, E. L. (1959). A restricted form of cerebellar cortical degeneration occurring in alcoholic patients. Arch. Neurol. (Chic.), 1, 579-688.

- , Collins, G. H., and Silby, H. (To be published.) The Wernicke-Korsakoff syndrome. A clinical and pathological study of 245 patients, 82 with post-mortem examinations. (To be published.)

Zimmerman, H. M. (1939). The pathology of the nervous system in vitamin deficiencies. Yale J. Biol. Med., 12, 23-28. 